\title{
Investigating the relationship between the lifestyle of parents and obese children and its comparison in single and multi-child families in primary schools of Mashhad City
}

\author{
Raziye Birjandi Bardsakan ${ }^{1}$, Farhad Adhami Moghaddam ${ }^{2}$, Mohammad Sahebalzamani $^{3}$ \\ ${ }^{1}$ MSc Student of Pediatric nursing, Tehran Medical Sciences, Islamic Azad University, Tehran, Iran \\ ${ }^{2}$ Associate professor, ophthalmologist, Tehran Medical Sciences, Islamic Azad University, Tehran, Iran \\ ${ }^{3}$ Associate professor, PhD of Educational Management, Tehran Medical Sciences, Islamic Azad University, Tehran, \\ Iran
}

\begin{abstract}
Background: Childhood obesity is associated with an increase in childhood morbidity, so that outpatient visits, hospitalization repetitions and the need for treatment in obese children are higher than non-obese children. The purpose of this study was to examine the relationship between parents' lifestyle and childhood obesity and its comparison in single and multi-child families.

Materials and methods: This study was a descriptive-correlation on 400 primary school students in Mashhad City in a multi-stage cluster sampling method based on the purpose. A questionnaire consisting of three sections of demographic, researcher-made LSQ lifestyle, and a Dianna bavmerind parenting method was used.

Results: There was a significant relationship between dimensions of lifestyle of families and obesity of children in some dimensions, so that significant negative correlation was found between physical health, sleep and rest, exercise and health, weight and nutrition control, disease prevention and environmental health, and BMI of children $(\mathrm{p}=0.001)$. In terms of psychological, mental, social health, drug avoidance, and prevention of events, no significant relationship was seen regarding the BMI of children. There was a significant difference between lifestyle dimensions in single child families and multiple children ones $(\mathrm{p}=0.001)$. There was no correlation between different styles of parenting and BMI in obese children $(\mathrm{P}>0.05)$.

Conclusion: Training parents about the causes of obesity in children and also monitoring children in their family, school, and environment can be effective in improving their lifestyle.

Keywords: Obesity, Child, Lifestyle, Single-child family, Multi-child family.

Cited as: Bardsakan B, Adhami Moghaddam F, Sahebalzamani M. Investigating the relationship between the lifestyle of parents and obese children and its comparison in single and multi-child families in primary schools of Mashhad City. Medical Science Journal of
\end{abstract} Islamic Azad University, Tehran Medical Branch 2020; 30(2): 185-192.

Correspondence to: Farhad Adhami Moghaddam

Tel: +989121301060

E-mail: fadhami@iautmu.ac.ir

ORCID ID: 0000-0003-4811-443x

Received: 15 Jun 2019; Accepted: 2 Jul 2019 
مجله علوم يزشكى دانشگاه آزاد اسلامى

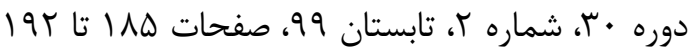

Original

Article

\section{بررسى ارتباط سبك زندكى والدين با جاقى كودكان و مقايسه آن در خانوادههاى تك و جند فرزندى در مدارس ابتدايى شهر مشهد}

راضيه بيرجندى بردسكن'، فرهاد ادهمى مقدمّ، محمدصاحب الزمانى

'دانشجوى كارشناس ارشد يرستارى كودكان، علوم يزشكى تهران دانشعاه آزاد اسلامى، تهران، ايران

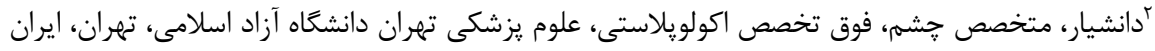

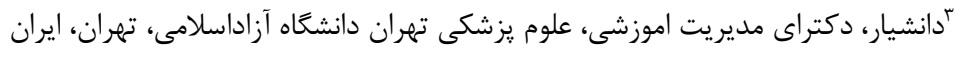

جـكيده

سابقه و هدف: جاقى كودكان، همراه با افزايش موربيديتى در كودكى /ست، به طورى كه مراجعات سريايى، دفعات بسترى و نياز به إنه

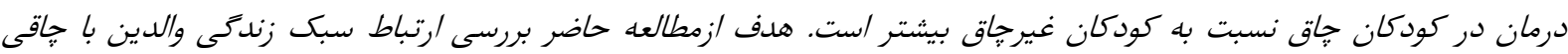

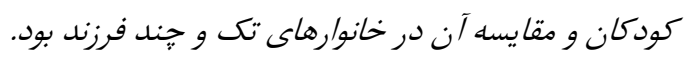

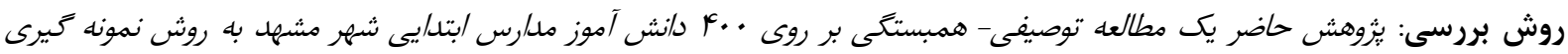

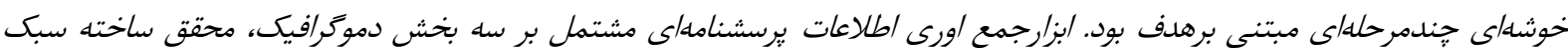

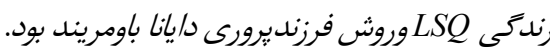

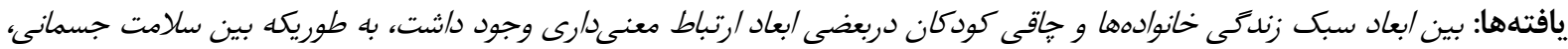

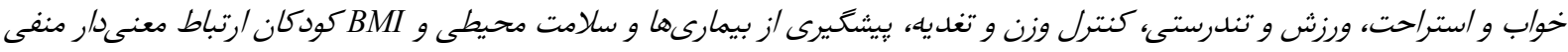

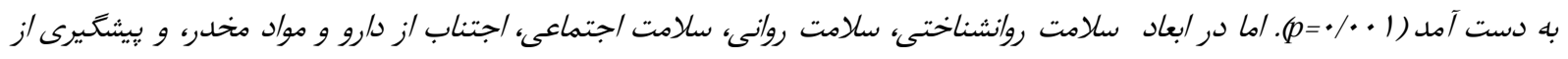

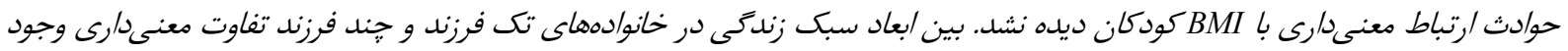

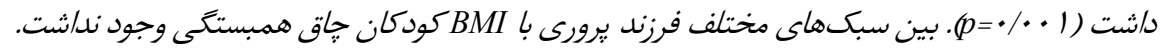

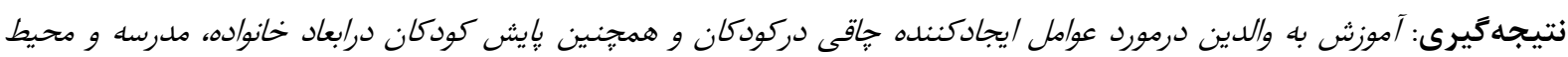

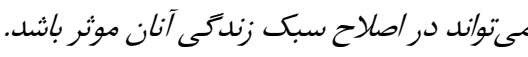

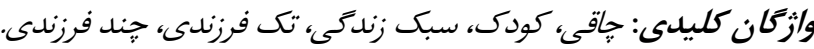

سطح سلامت و رفاه فرد مىشود (T). در حال حاضـر جـاقى و مقدمه

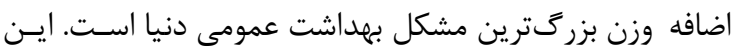

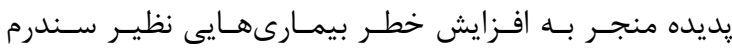
متابوليك، بيمارىهاى قلبى-عروقى، اختلالات تنفسى، بيمارى

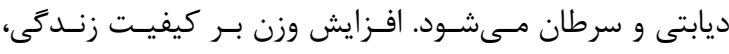
آموزش و درآمد نيز تأثير مى كذارد (بان).

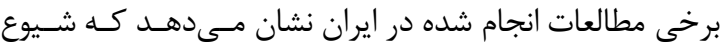

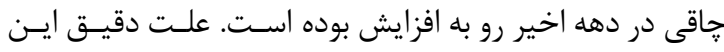

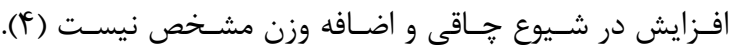
به طور كلى سبك زندگى يعنى مجموعهاى از نكَرشها عـادات

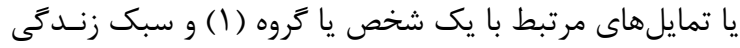

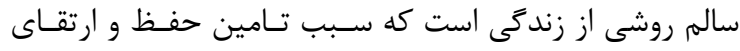
آدرس نويسنده مسئول: تهران، دانشخاه آزاد اسلامى علوم يزشكى تهران ، فرهاد ادهمى مقدم (email: fadhami@iautmu.ac.ir) ORCID ID: 0000-0003-4811-443x

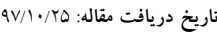

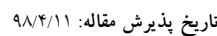


برسشنامه سه قسمتى شامل مشخصـات دموكرافيـك، يرسشـنامه

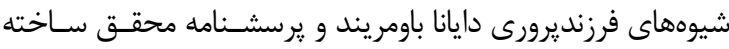

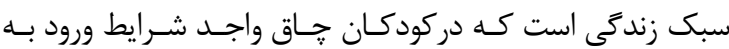

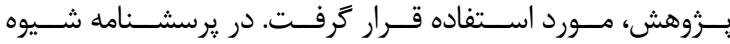

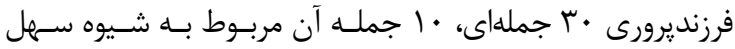

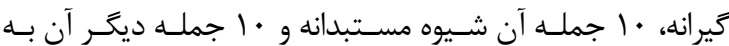
شيوه قاطع و اطمينان بخش اختصاص دارد. در مقابل هــر عبـارت

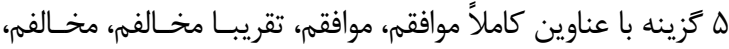

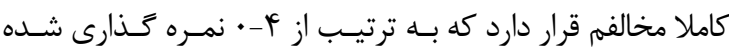
است. شيوه سـهل گيرانـه شـامل سـوالات

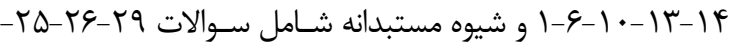
|1

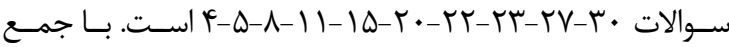
نمرههاى سوالات مربوط به هرشيوه سه نمره مجزا درمـورد شـيوه

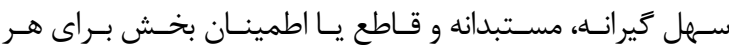
آزمودنى به دست مى آيد. بالاترين نمـرهاى كـهـ بـين شـيوههـا بــهـ

دست مى آيد، شيوه فرزند يرورى والدين را مشخص مى به بند.

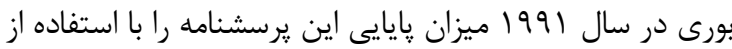

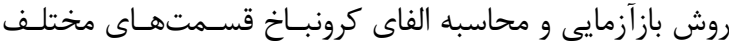
يرسشنامه بدين شـرح حَزارش كـرد: ||||• بـراى شـيوه سـهل

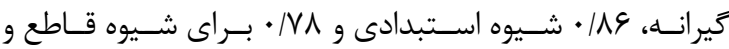
اطمينان بخش كه در هر شيوه نشانگر ريايايى بالاى آزمـون بـود. بورى اعتبار يرسشنامه را از روش اعتبار افتراقى محاسـبه كـرد و

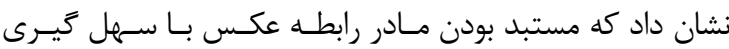

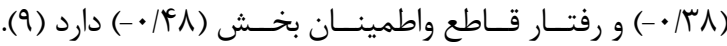
تنكــابنى بنــد يـى (I IV9 ) اعتبــار شـيوه فرزنــد يـرورى را در يثرهشى بر روى جمعى از دانش آموزان شهر تهران بررسى كرد.

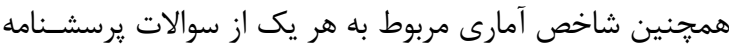
محاسبه شـد و بـراى بررسـى همســان سـازى درونسى سـوالات

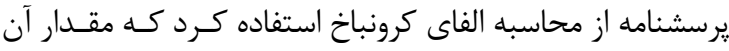

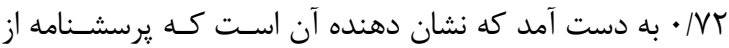

$$
\text { يايايى مناسبى برخوردار است ( • (1). }
$$

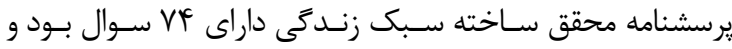

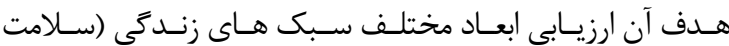
جسمانى، ورزش و تندرستى، كنتـرل وزن و تغذيـه، ٍيشــيرى از

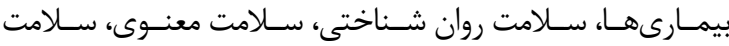

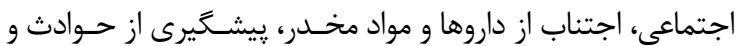
سلامت محيطى) بود. طيف ياسـخگَويى آن از نــوع ليكـرت بـود و نحوه نمره كذارى آن بدين ترتيب بود كه به گزينه هر

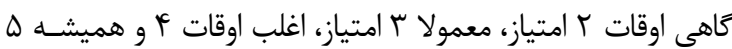

اهميت جاقى در دوران كودكى نه تنها به دليل عوارض جسمى و روانى زودرس، بلكه به دليل افزايش جاقى بزرگسالى، افزايش

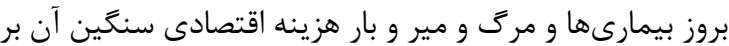
اجتماع است (ه) زندگى بى تحرى يكى عامل اساسى و تسهيل كننده در بروز اضافه وزن و جاقى كودكـان محسـوب مسى شــود

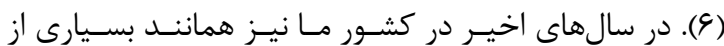
كشورهاى در حال توسعه، از يك سو، فعاليت جسمانى كودكان

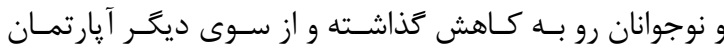
نشينى، تماشاى تلويزيون و بازىهاى رايانهاى و نيز مصرف مواد رونه غذايى يركالرى افزايش يافته است (9). مداخلات ارايه شده براى كاهش وزن و فعاليت فيزيكى بيشـتر

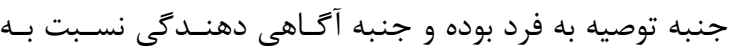
عوارض جاقى و ضرورت انجام فعاليت بوده است و كمتـر سـاير افراد در برنامه كاهش وزن كودى مشاركت داشـتند. بنـابراين،

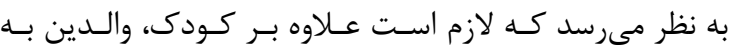
خصوص مادر، در برنامـه شـركت داده شـوند (9) در مطالعـات انجام شده درباره عوامـل مـوثر بـر جــاقى در كودكـان متوجــهـ

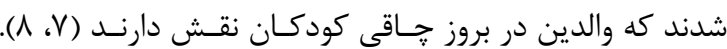
فزايش آكاهى عمومى در مورد اصـلاح شـيوه زنـدى بـى بـا كـم

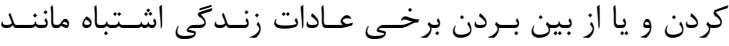
مصرف غذاهاى آماده، مصرف ميان وعدهها، مصـرف دخانيـات، مواد الكلى و هم جنين توصيه به برخى عادات بهداشتى، مانند ستراحت كافى و در عين حال انجام فعاليتهاى ورزشى منظم در طول هفته مى تواند از جمله مهمترين راهكارها بـراى يـيش كيرى و كنترل جاقى و اضافه وزن در افراد باشد. بــا توجـهـ بــهـ مطالب بيان شده و اهميت بررسى ارتباط سبك زندگى والدين

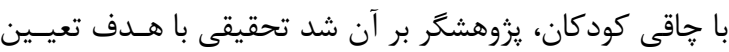

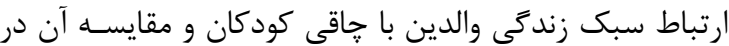
خانوارهاى تك و جند فرزند انجام دهد.

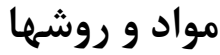

يزوهش حاضر از نوع مقطعى به روش توصـيفى همبسـتخى بـود.

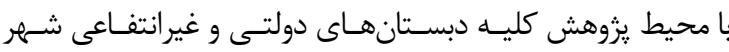
مشهد و جامعه مورد نظر در ايسن يـرزوهش شـامل كليـه كودكـان جاق دبستانهاى شهر مشهد با معيارهاى يزوهش، شـامل سـن

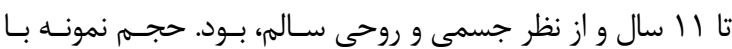
توجه به فرمول

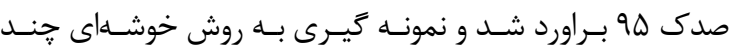

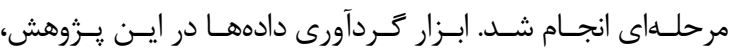




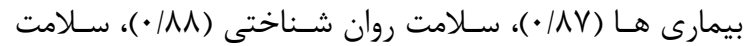

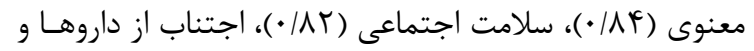

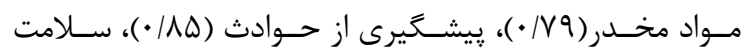

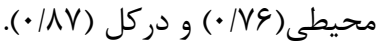

جهت انجام يزوهش، يزوهشگران بعد از اخذ معرفى نامه كتبى

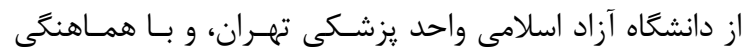

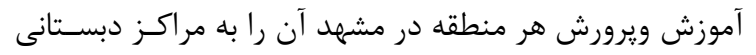

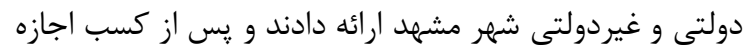

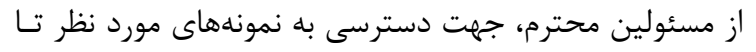

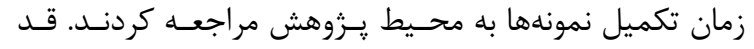

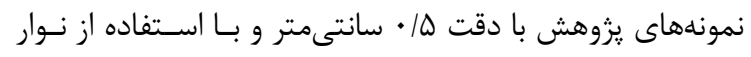

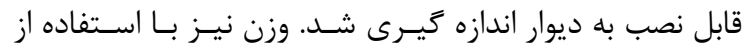
ترازوى ديجيتال با لباس سبك و بدون كفش اندازه گيرى شد.

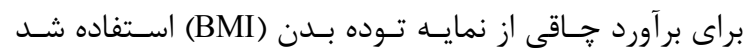

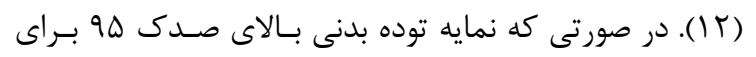

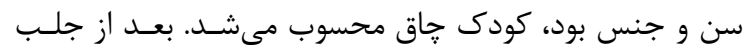

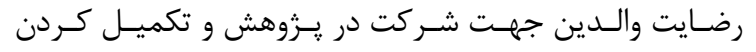

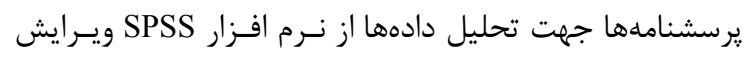
r r استفاده شد. براى تعيين ارتباط شيوههاى فرزنـديرورى يـاـ

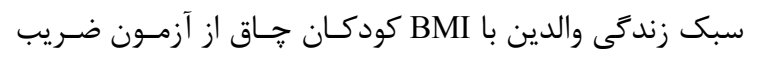
همبستكى پيرسن يا اسييرمن و براى مقايسه ارتباط شيوههاى

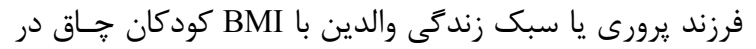

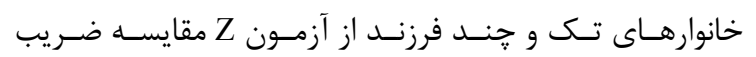
همبستخى دو جامعه استفاده شد. سطح معنى دارى برابر هـ • • •

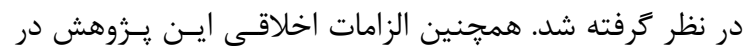

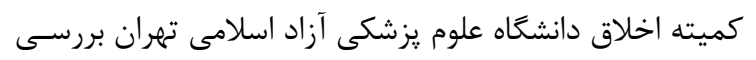

امتياز تعلق گرفت. اين يرسشنامه داراى || بعـد بـود كـه شـامل

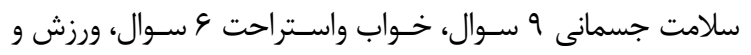

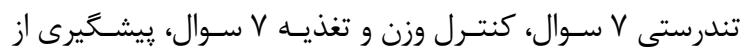

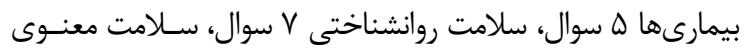

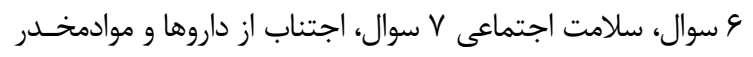

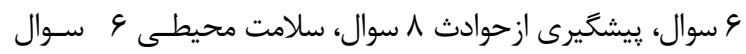

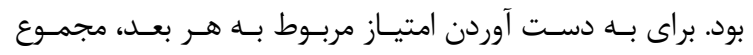

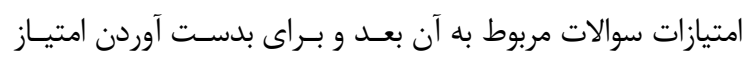

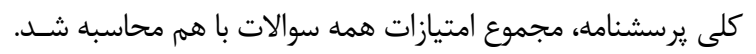
نسخه اوليه يرسشنامه سبك زندگى توسـط لعلى و همكـاران در

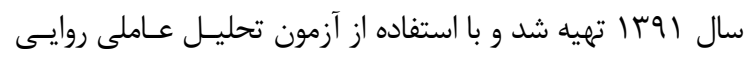

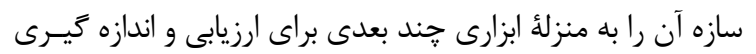

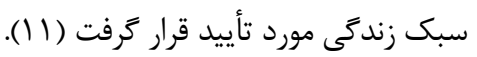

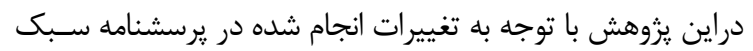

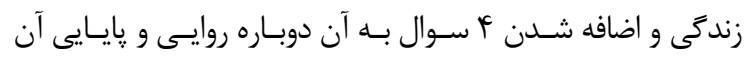

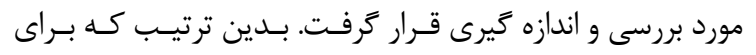

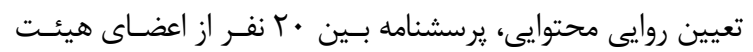

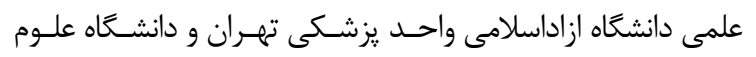

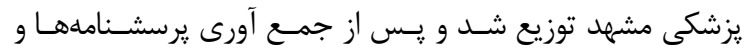

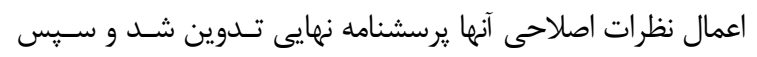

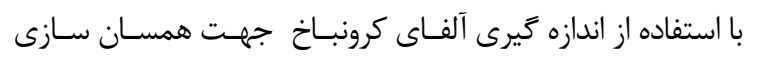

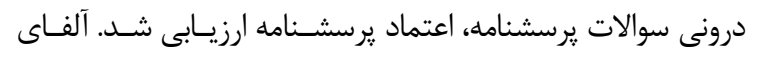
كرونباخ يرسشنامه سبك زندگى محقق سـاخته مختلف عبارت بودند از:

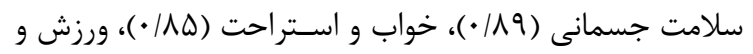

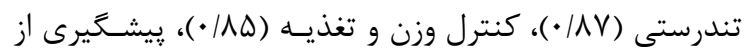

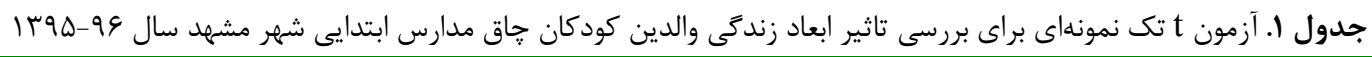

\begin{tabular}{|c|c|c|c|c|c|c|c|c|}
\hline ت ت ت اثير & سطح معنى & تفاوت ميانگين با ارزش آزمون & $\mathbf{t}$ & انحراف & ميانغين & فرضانگين & تعداد & ابعاد سبك زندگى \\
\hline معنى دار & $<\cdots+$ & $-\cdot / V \Delta$ & $1 \cdot 1911$ & . /AT & $r / V I$ & r & $f \ldots$ & سلامت جسمانى \\
\hline معنى دار & $<\cdots 1$ & $-\cdot|9|$ & $\mid r / \cdot r \Delta$ & $\cdot / V \mu$ & $r / \Delta T$ & r & r.. & خواب و استراحت \\
\hline معنى دار &.$/ r$ & $-\cdot|V|$ & $|1 / r| r$ &.$/ 91$ & $\mid / 91$ & r & f.. & ورزش و تندرستى \\
\hline معنى دار & $<\cdots \mid$ & $-\cdot / A V$ & $\mid \mathrm{V} / \cdot 1 \mathrm{Q}$ & .190 & I/AV & r & $f \cdot$. & كنترل وزن و تغذيه \\
\hline معنى مار & $.1 \cdot 1 \mathrm{~F}$ & - & Q/4 & .190 & $T / \mu \Delta$ & r & f.. & ييشَيرى از بيمارى ها \\
\hline - & . $/ \Delta T^{\prime} q$ & $\cdot / \cdot r \Delta$ & | (बा & I/VT & 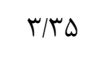 & r & f.. & سلامت روان شناختى \\
\hline- & $\cdot /$ mFF & $\cdot 11$ & $-1 / M F Y$ & $\cdot / 19$ & $r / \Delta \mid$ & r & $r \ldots$ & سلامت معنوى \\
\hline - &.$/ 14$ & $\cdot / V F$ & $-T / T)$ & $\cdot / V \Delta$ & r/^q & r & $r \ldots$ & سلامت اجتماعى \\
\hline - & $\cdot / T F$ & $\cdot / \Lambda V$ & $-1 / 494$ & $1 / \Delta \Lambda$ & r/^q & r & $r \ldots$ & اجتناب از داروها و مواد مخدر \\
\hline - & $\cdot / \cdot \wedge \vee$ & -.190 & -V/ARt & $\cdot / 19$ & $r / 9 \Delta$ & r & $r \ldots$ & ييشكيرى از حوادث \\
\hline معنى دار & $\cdot 1 \cdot \cdot 1$ & $\cdot / D F$ & $|r /| \cdot r$ & $1 / 91$ & $\mu / \mu$ & r & f.. & سلامت محيطى \\
\hline
\end{tabular}


مجموع درصد والدين شركت كننده در يزوهش كه جندفرزند

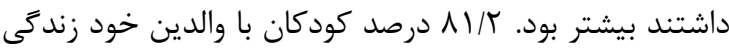
مى كردند كه بيشترين درصد را به خود اختصاص مى بـدادند و بود بودئ

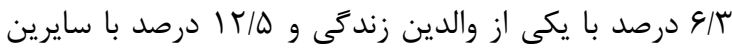
زندگى مى كردند.

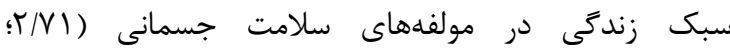

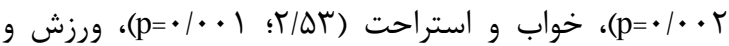

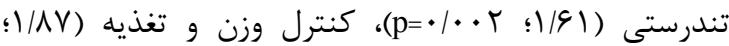

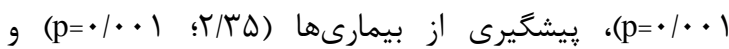

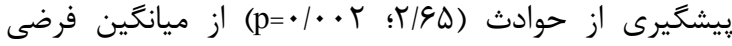
كمتر بود و در وضعيت نامطلوبى قرار داشت، ولى در مولفههاى

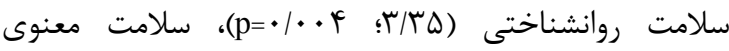
( إها

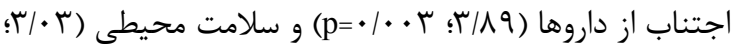

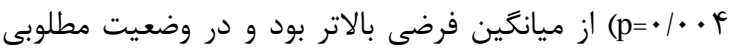

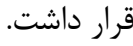

بر اساس جدول ا با توجه به t به دست آمده مىتوان كفت با

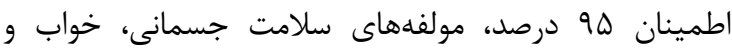
استراحت، ورزش و تندرستى، كنترل وزن و تغذيه و بيشخيرى از بيمارىها و يِيشيرى از حوادث در وضعيت نامطلوبى قرار
شـد و بــر اسـاس كـد IR.IAU.TMU.REC.1395.105 مــورد تاييد قرار كرفت.

بافتهها

از بين · F دانش آموز بيشترين فراوانى شركت كنندكان

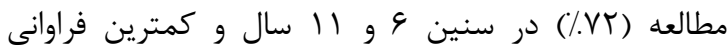
شركت كننده در اين مطالعه (FF/F) سنين • •ا سال بود. هله

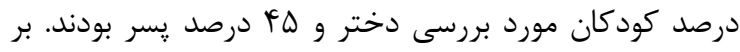

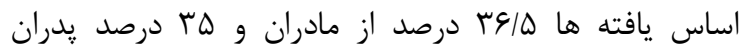
تحصيلات كاردانى داشتند كه بيشترين درصد را داشتند. درصد مادران 8 ابتدايى و ك/T درصد از يدران بىسواد بودند

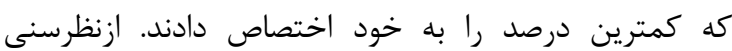
بيشترين گروه سنى مادران شركت كننده در يزوهش در گروه

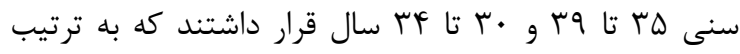

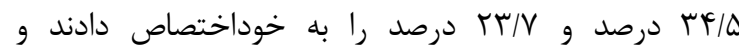
بيشترين گروه سنى يدران شركت كننده دريزوهش در زروه

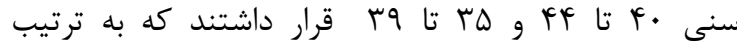

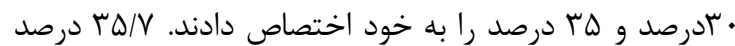
خانوادهها تك فرزند بودند و س/ع بع درصد خانوادهها جند فرز بودند. در اين ميان، د/اس درصد خانوادهها r فرزند داشتند. در برك

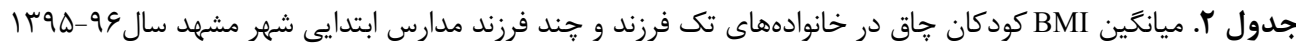

\begin{tabular}{|c|c|c|c|c|c|c|}
\hline سطح معنى دارى & مقدار t & درجه آزادى & اختلاف ميانگينها & ميانگَين نمونه & تعداد & BMI كودكان خاق BMI \\
\hline$\cdot 1 \cdot 4$ & $r / \cdot r$ & IFT & $r / T$ & rQ/बV & Ifr & در خانواده هاى تك فرزند \\
\hline$\cdot 1 \cdot \mathrm{F}$ & $1 / 99$ & $r \Delta \varphi$ & $r / q$ & $r V / Q D$ & rDV & در خانواده هاى جند فرزند \\
\hline
\end{tabular}

جدول س. ارتباط بين شيوه هاى فرزنديرورى و BMI كودكان خاق مدارس ابتدايى شهر مشهدسال و9-هوس|

\begin{tabular}{|c|c|c|c|}
\hline سبك مقتدر انه & سبك مستبدانه & سبك سهل تيرانه & شيوه هاى فرزند يرورى \\
\hline$r=\cdot / r \Delta$ & $\mathrm{r}=\cdot|r|$ & $r=\cdot / 1 r$ & كودكان BMI \\
\hline $\mathrm{p}=\cdot / \cdot \vee \Delta$ & $\mathrm{p}=\cdot 1 \cdot 9 \Delta$ & $\mathrm{p}=.|\cdot .9|$ & \\
\hline
\end{tabular}

جدول F. آزمون t دو نمونه مستقل براى مقايسه شيوههاى فرزنديرورى والدين فرزندان جاق در خانوادههاى تك فرزند و گجند فرزند مدارس

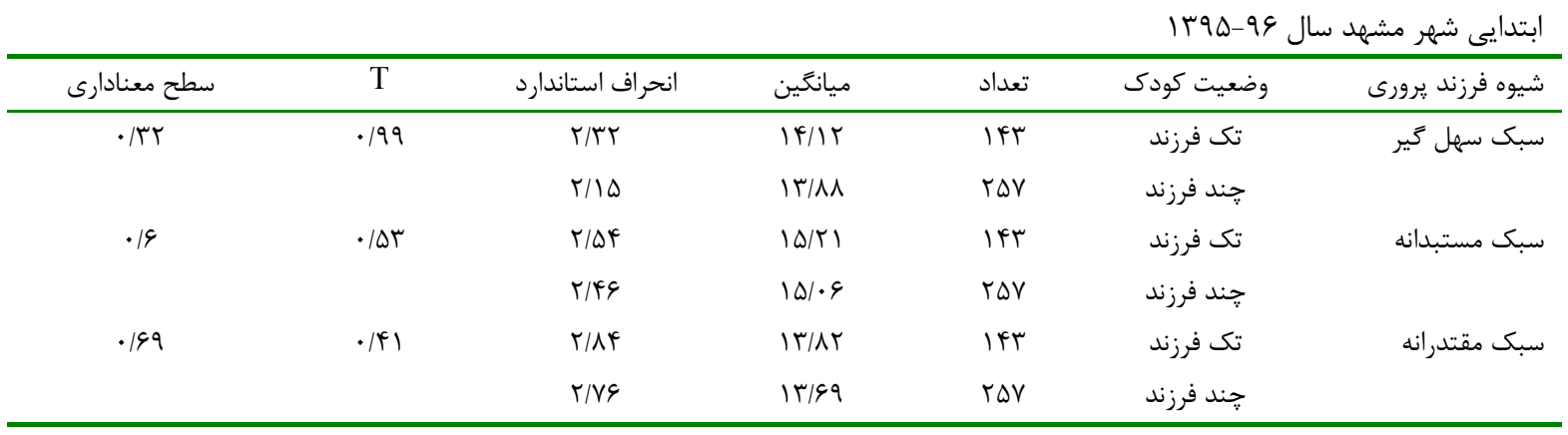




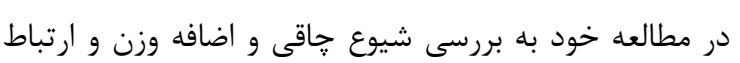

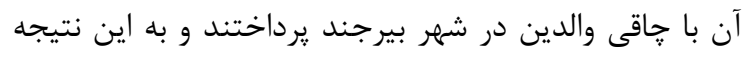

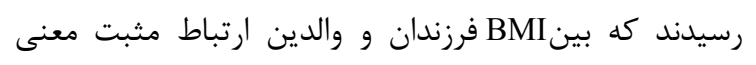

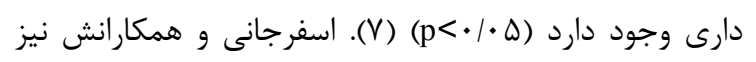

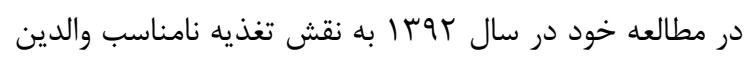

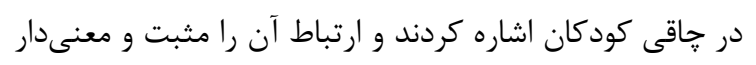

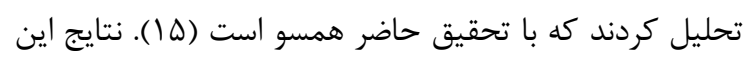

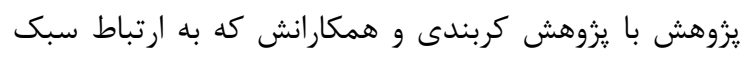

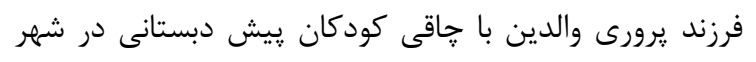

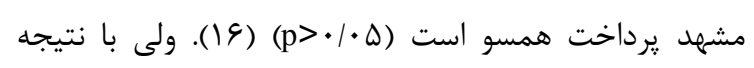

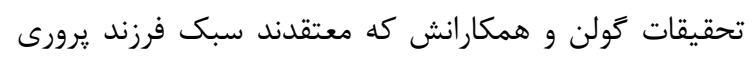

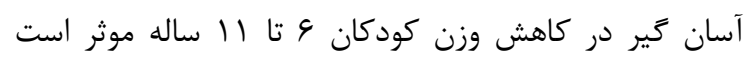

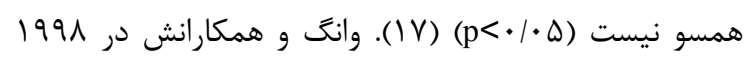

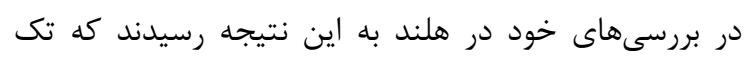

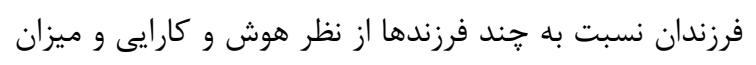

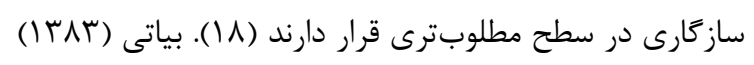

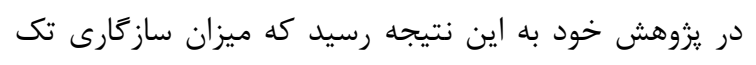

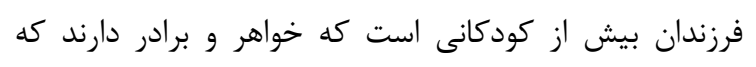

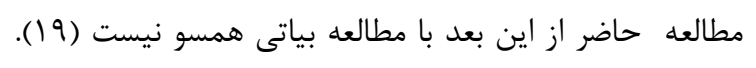

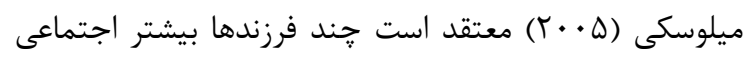

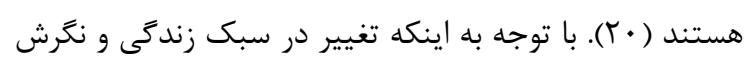

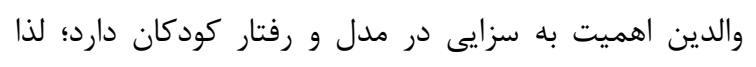

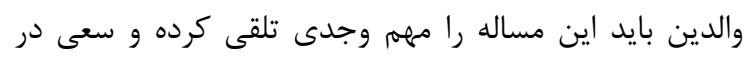

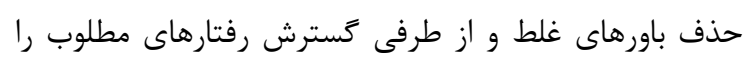

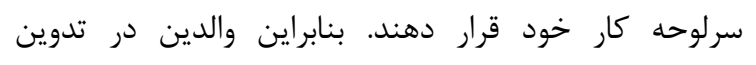

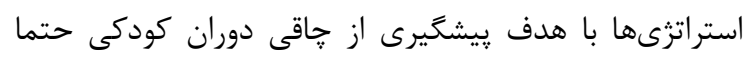

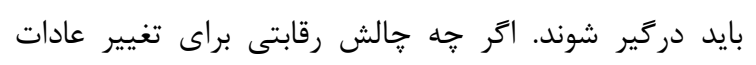

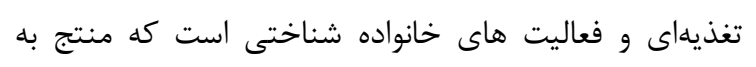

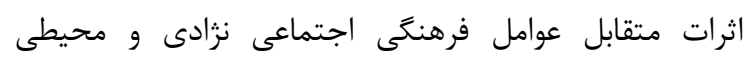
مىشود. با توجه به نتايج يزوهش حاضر نتيجه كَيرى مىشود كه بين

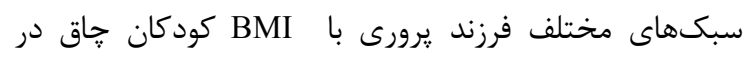

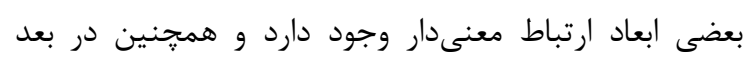

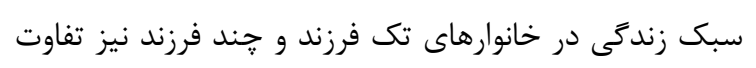

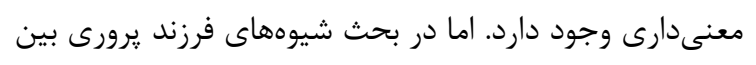

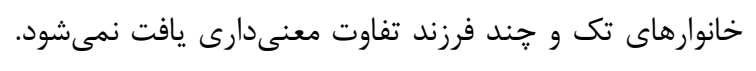

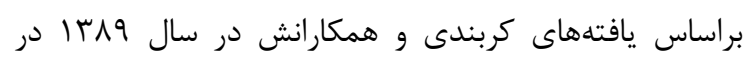

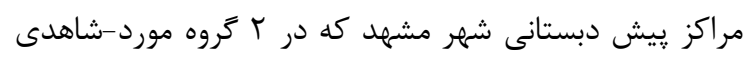

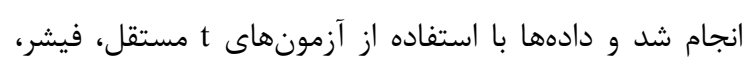

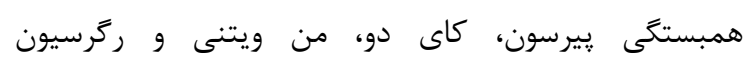

\section{دارند.}

براساس جدول Y متوسط BMI كودكان در خانوادههاى تك

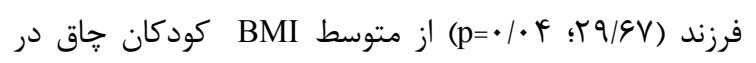

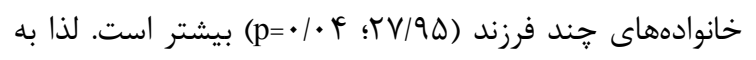

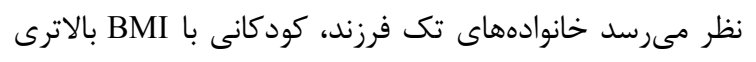
داشتند. بر اساس يافتههاى جدول r مشاهده شد كه بين سبكهاى

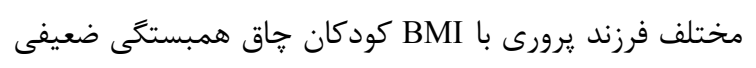

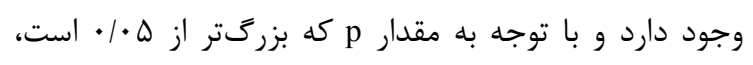
ارتباط معنى دارى وجود ندارد.

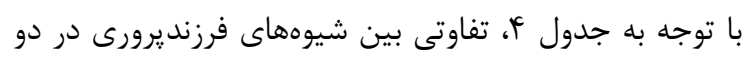

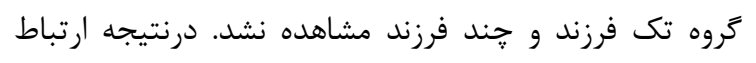

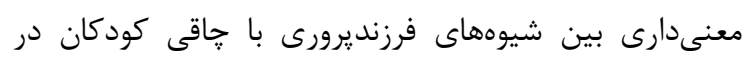

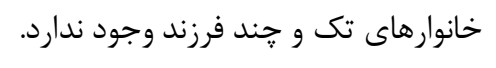

\section{بحث}

يافتههاى اين يزوهش نشان داد كه بين ابعاد سبك زندكى إنى

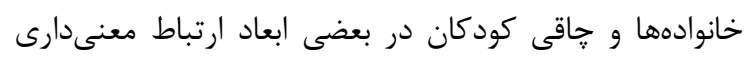

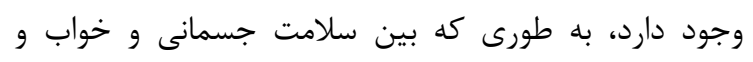

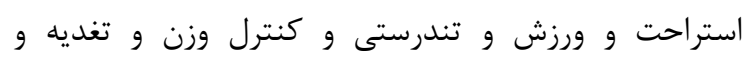
يُشكيرى از بيمارىها و سلامت محيطى و و BMI كودكان

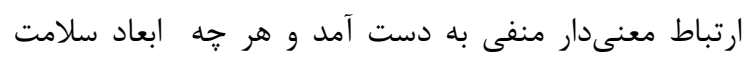

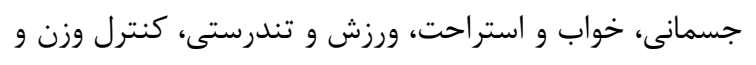

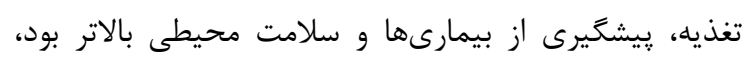

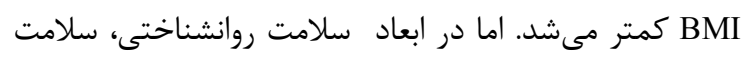

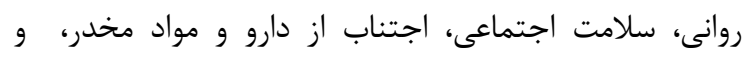

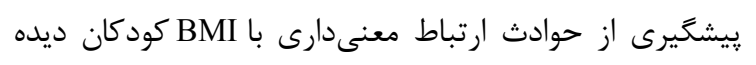

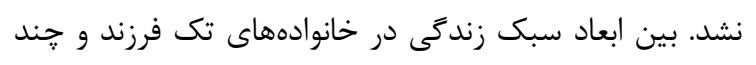

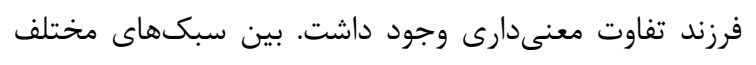

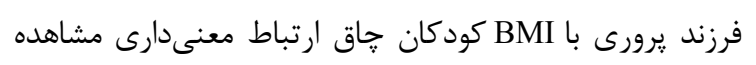
نشد.

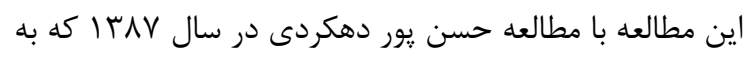

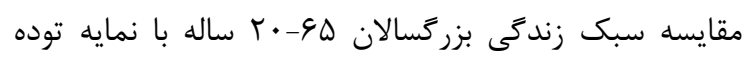

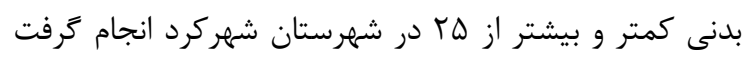

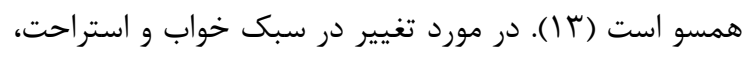

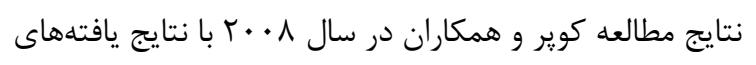

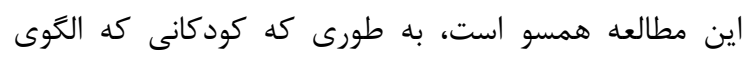

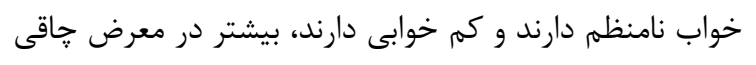

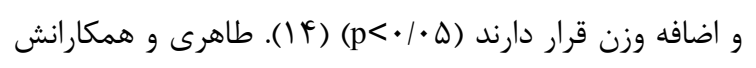




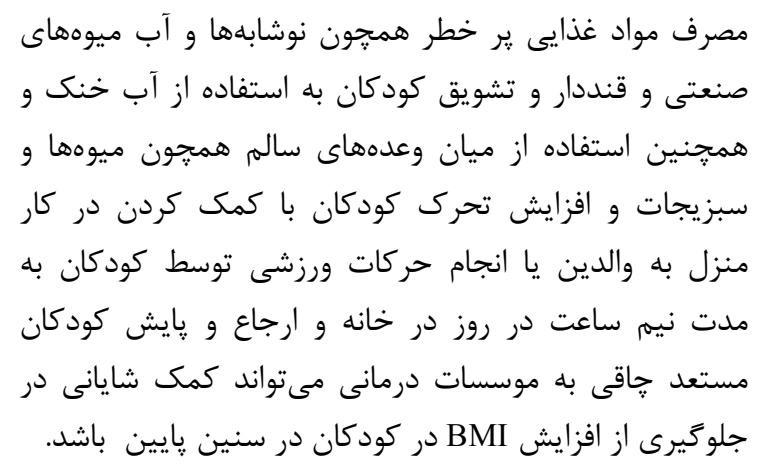

\section{REFERENCES}

1. Safari M, Amini NM, Eftekhar Ardebili H, Mahmoudi M, Sanayee Nasab H. Evaluation of educational intervention based on perceed proceed model for promoting lifestyle in adolescents. Scientific Journal of Daneshvar Pezeshkie Journal 2012; 19: 1-11. [In Persian]

2. Hekmat Pour D, Shamsi M, Zamani M. Reviewing effect of healthy lifestyle education program on elderly life quality in Arak city. Research Science Journal of Arak University of Medical Sciences 2013; 16: 1-11. [In Persian]

3. Nigro E, Scudiero O, Monaco ML, Palmieri A, Mazzarella G, Costagliola C, et al. New insight into adiponectin role in obesity and obesity-related diseases. Biomed Res Int 2014; 2014:658913.

4. Mirsuleimani H, Mokhtari Lake N, Mirhadian L, Kazemnejad Lili E. Survey of overweight and obesity predictors in children attending in primary schools in Rasht city. Comprehensive Nursing and Midwifery 2014; 25: 55-62 [In Persian]

5. Porshokoh N, Hassan Doust N, Moadab F, Rezaei A. Prevalence of obesity in Iranian children and its related factors. International Congress on Mother and Child Obesity, Urumia city, 2015. [In Persian]

6- Jafarzadeh S, Mohammad Khan Kermanshahi S, Hajizadeh I. Investigating the impact of health promotion program with participatory approach on weight of primary school overweight girls. Journal of Fasa University of Medical Sciences. [In Persian]

7- Taheri F, Kazemi T, Ansari Nejad T, Sharifzadeh Gh. Prevalence of obesity and overweight in children and its relation with obesity of parents in Birjand city. Journal of Birjand University of Medical Sciences 2014;21: 370-376. [In Persian]

8-Bhuiyan MU, Zaman S, Ahmed T. Risk factors associated with overweight and obesity among urban school children and adolescents in Bangladesh: a case-control study. BMC Pediatr 2012; 13:12-19.

9- Buri JR. Parental authority questionnaire. J Pers Assess 1998;57:110-119.

10-Tonekaboni Bandpei A. Reviewing relationship between parenting methods and social motivation, the motivation for progress of high school students in Tehran [Master's thesis]. Tehran: Islamic Azad University, Tehran Center Branch; 2000.

11-Laali M, Abedi A, Kajbaf MB. Making and validation of LSQ lifestyle questionnaire. Psychol Res 2000; 15: 1-14.

12-Taheri F, Kazemi T, Ansari Nejad T, Sharifzadeh Gh. Prevalence of obesity and overweight in children and its relationship with parental obesity in Birjand. Journal of Birjand University of Medical Sciences 2015;21: 376-370. [In Persian]

13 - Hasanpour Dehkordi A, Shouhani M, Salehian T, Safdari Dehsheshmeie F, Foruzandeh N, Naderipour A, et al. Comparing lifestyle of adults aged 20-65 years with a BMI more or less than 25 in Shahrekord. Journal of Shahrekord University of Medical Sciences 2015; 12:24-33.

14-Cooper Z, Fair burn CG, Hawker DM, Editors. Cognitive behavioral treatment of obesity: a clinician s guide. New York: Guilford Press; 2010.

15-Esfarjani M, Khalafi M. An analysis of factors affecting the success of lifestyle interventions in obese children. Summary of the lectures in 10th Nutrition Conference, Tehran, Iran; 2013. P.22-21.

16. Karbandi S, Eshghizadeh M, Agha Mohammadian HR, Ebrahimzadeh S, Safarian M. Relationship between parenting style and obesity in preschool children in Mashhad city. Ofogh Danesh Magazine 2010;16: 33-39. [In Persian] 
17-Kitzmann KM, Dalton W, Buscemi J. Beyond parenting practices: family context and treatment of pediatric obesity. Family Rel 2008; 57:13-23.

18- Wang F, Wild TC, Kipp W, Kuhle S, Veugelers PJ. The influence of childhood obesity on the development of selfesteem. Health Rep 2009;20:21-27.

19. Bayat E, Rahimian Boogar I, Talepadsand S, Yousefi Chajian P. The effectiveness of family-based cognitivebehavioral therapy on weight loss in children with obesity. Journal of Endocrinology and Metabolism of Iran 2014; 16: 254-261.

20-Milevsky A, Schlechter M, Netter S, Keehn D. Maternal and paternal parenting styles in adolescents. Associations with self-esteem, depression and life-satisfaction. J Child Fam Stud 2005:16:39-47. 